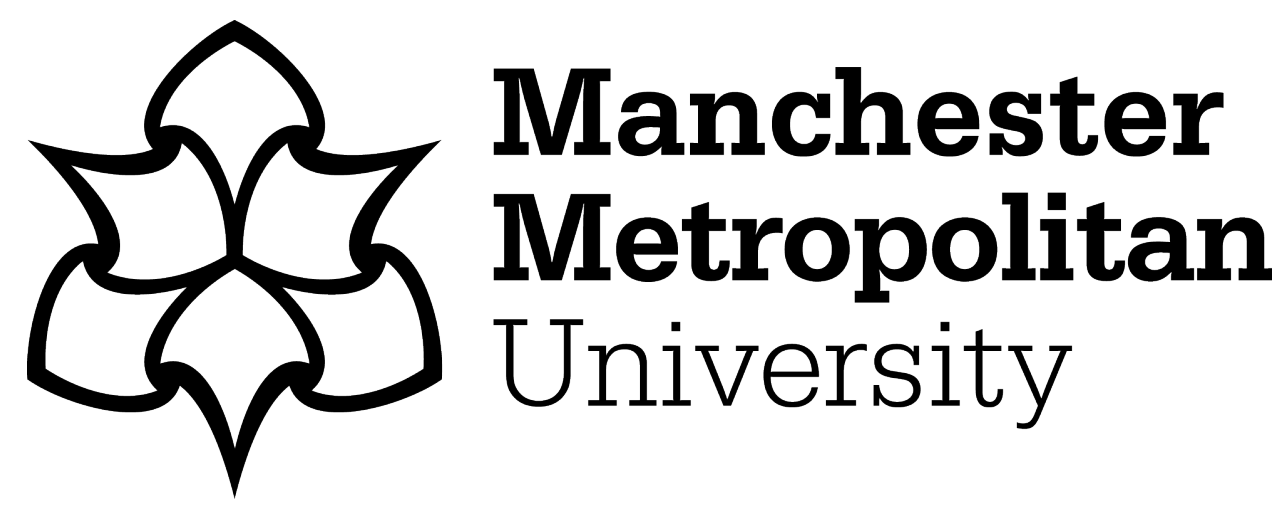

SIRRI, L and RÄMÄ, P (2019) Similar and distinct neural mechanisms underlying semantic priming in the languages of the French-Spanish bilingual children. Bilingualism: Language and Cognition, 22 (1). pp. 93-102. ISSN 1366-7289

Downloaded from: https://e-space.mmu.ac.uk/621990/

Version: Accepted Version

Publisher: Cambridge University Press (CUP)

DOI: https://doi.org/10.1017/S1366728917000578

Please cite the published version 


\section{Similar and distinct neural mechanisms underlying semantic priming in the languages of the French-Spanish bilingual children*}

LOUAH SIRRI

Université Paris Descartes, Sorbonne Paris Cité, Paris, France PIA R ÄM Ä

Université Paris Descartes, Sorbonne Paris Cité, Paris, France CNRS, Laboratoire Psychologie de la Perception (UMR 8242), Paris, France

(Received: September 1, 2016; final revision received: October 19, 2017; accepted: October 22, 2017)

Recent evidence demonstrates that lexical-semantic connections emerge over the second year of life for monolingual children. Yet, little is known about the developing lexical-semantic organization of children acquiring two languages simultaneously. Two- to 4 year-old French-Spanish bilingual children completed a within-language auditory semantic priming task in both of their languages, while event-related potentials (ERPS) were recorded. The results revealed that bilingual children exhibited sensitivity to taxonomic relationships between words in each of their languages, but the pattern of brain activity varied across the dominant $(D L)$ and the non-dominant $(N D L)$ languages. While the N2 occurred for both languages, the N400 appeared for target words in the DL only and the late anterior negativity for target words in the NDL only. These findings indicate that words are organized taxonomically in the bilinguals' lexicons. However, the patterns of brain activity suggest that common and distinct neural resources underlie lexical-semantic processing in each language.

Keywords: bilingualism, lexical-semantic processing, language-related ERPs

\section{Introduction}

There is accumulating evidence related to early dual language acquisition that suggests infants raised bilingually reach their language milestones at the same age as their monolingual peers (e.g., for an extended review, see Genesee, 2006). For instance, in both linguistic groups, phonological perception (Bosch \& Sebastian-Galles, 1997, 2001), use of prosodic cues (Gervain \& Werker, 2013), word segmentation (Polka \& Sundara, 2003), onset of canonical babbling (Oller, Eilers, Urbano \& Cobo-Lewis, 1997), and first word production (Genesee, 2003; Patterson \& Pearson, 2004) occur at the same age. Additionally, it has been shown that bilingual children's overall rate of vocabulary acquisition falls within the same range as those who are monolinguals (Pearson, Fernandez \& Oller, 1993). Nevertheless, the developing lexical-semantic system organization of bilingual children remains underinvestigated in comparison with other linguistic domains

\footnotetext{
* We thank all families for their participation and contribution to this research. This research was funded by the Sorbonne Paris Cite Grant, PME DIM Cerveau et Pensée 2013, and LABEX EFL (ANR-10LABX-0083).
}

(e.g., for a review, see DeAnda, Poulin-dubois, Zesiger \& Friend, 2016a). In particular, it remains to be investigated whether bilingual children organize words acquired in each of their languages according to semantic relatedness, thus exhibiting sensitivity to the relationship between word pairs for both languages.

Behavioural and neurophysiological studies with monolingual children have shown that over the second year of life, both accuracy and speed of familiar word recognition increase along with vocabulary growth, resulting in more robust lexical representations (e.g., Fernald, Pinto, Swingley, Weinberg, McRoberts, 1998; Fernald, Perfors \& Marchman, 2006). In addition, increased vocabulary and word comprehension were shown to influence the patterns of brain activity in response to known words (Mills, Coffey-Corina \& Neville, 1993, 1997). Mills and colleagues (1993, 1997) compared event-related potentials (ERPs) in response to words that could be understood by children with words that could not at 13- to 17-, and 20-months of age. Their results revealed that there were important changes in the organization of neural activity patterns linked to language skills across the second year of life. First, the amplitudes of three ERP components, N200, N350, and N600-900 were more negative to known than to unknown words, 
demonstrating that these ERP components are associated with word comprehension. Second, increased language abilities were shown to correlate with left hemispheric distribution of these components: While at 13- to 17months of age, the ERPs were broadly distributed from anterior to posterior recording sites and from left to right hemisphere; at 20-months, the ERPs were more pronounced over temporal and parietal recording sites of the left hemisphere. These findings suggest that language competency is linked to the specialization of neural systems underpinning word comprehension.

The second year of life is also marked by an accelerated rate of word learning and production (e.g., Bloom, 1973; for a review, see Ganger \& Brent, 2004). Children become more efficient in understanding word meanings (e.g., Elman, Bates, Johnson, Karmiloff-Smith, Parisi \& Plunkett, 1996; Fernald et al., 2006) and organize words into clusters based on shared semantic features (e.g., Hills, Maouene, Maouene, Sheya \& Smith, 2009). Recently, it has also been shown that monolingual children exhibit sensitivity to the semantic relationship between word meanings, such as associative (e.g., Arias-Trejo \& Plunkett, 2009; Styles \& Plunkett, 2009) and/or taxonomic (e.g., Arias-Trejo \& Plunkett, 2013; Rämä, Sirri \& Serres, 2013; Delle Luche, Durrant, Floccia \& Plunkett, 2014; Sirri \& Rämä, 2015). For example, 18month-old monolinguals listened to lists of taxonomically related words (e.g., biscuit-milk-apple) for longer than to lists of unrelated (e.g., bib-finger-coat) words (Delle Luche et al., 2014). Furthermore, in a primed intermodal preferential looking (IPL) task, increased looking times were obtained for target images that were semantically related to the prime word at 21- and 24-months of age (e.g., Arias-Trejo \& Plunkett, 2009, 2013; Styles \& Plunkett, 2009). Similarly, ERP studies with 18- (Sirri \& Rämä, 2015) and 24-month-old children (Torkildsen, Syversen, Simonsen, Moen \& Lindgren, 2007; Rämä et al., 2013) have shown that the N400 component (shown to reflect semantic violations; for an extended review, see Kutas \& Federmeier, 2011) in response to spoken words was more pronounced for taxonomically unrelated than for related word-pairs. These few findings suggest that taxonomic relationships emerge as children enter the period of accelerated word learning.

Children acquiring two languages simultaneously face the challenge of learning a second language even before the first language has been fully mastered. As their linguistic exposure is shared between two languages, they have less experience with words in each language compared to their monolingual peers, which might influence the activation and/or the structure of their lexical-semantic system in each of their languages. Speed of word processing has been recently shown to increase at a similar rate for bilinguals in their dominant (hereafter: DL) and the non-dominant (hereafter: NDL) languages and for monolinguals from 16 to 22 months of age (DeAnda, Hendrickson, Zesiger, Poulin-Dubois \& Friend, 2016b), while speed of familiar word recognition was related to the vocabulary knowledge within each of the bilingual child's languages (Marchman, Fernald \& Hurtado, 2010; Hurtado, Grüter, Marchman \& Fernald, 2014; Legacy, Zesiger, Friend \& Poulin-Dubois, 2016).

Conboy and Mills (2006) explored the same ERP components (N200-400, N400-600, and N600-900) as in Mills et al. $(1993,1997)$ in response to known and unknown words in each of the 19- to 22-month-old bilinguals' languages. The results showed that the three components were more pronounced for known than for unknown words, but occurred earlier for the DL compared to the NDL and their distribution varied across languages. The anteriorly distributed N200-400 was larger over the right than over the left hemisphere in the DL but not in the NDL. While in the DL the N400-600 was broadly distributed, in the NDL it occurred over the left anterior and right posterior regions. On the contrary, the N600-900 was broadly distributed and its magnitude did not vary across the DL and the NDL. According to the authors, latency differences are linked to linguistic abilities, meaning that increased experience with one language contributes to the speed of word processing in that language. It was also suggested that the different ERPs distribution across languages reflects allocation of attention when integrating two languages, indicating that distinct neural generators might be engaged during lexical processing of the two languages (Conboy \& Mills, 2006). In another study, only latency differences across the DL and NDL in bilingual infants were found: Eleven-montholds displayed the N2 and N4 components in response to familiar words both in their DL and NDL, but the components occurred later in the NDL, suggesting faster neural processing in the DL (Vihman, Thierry, Lum, Keren-Portnoy \& Martin, 2007).

Using a behavioural primed IPL task, semantic priming was evidenced only for the DL and when prime words were in the DL and target words in the NDL, suggesting that semantic representations are stronger in the DL than in the NDL and, consequently, words in the DL are processed more efficiently than words in the NDL (Singh, 2014). The author also suggested that the links between words and their meanings are better established in the DL than in the NDL, which might result in semantic facilitation in that language (Singh, 2014). The current study aimed to extend the above-mentioned findings and investigate whether children exposed to two languages simultaneously integrate semantic relationships between words similarly in each of their languages by using the ERP technique. Two- to 4-year-old bilingual children listened to prime-target word pairs that were either taxonomically related or unrelated both in French and in Spanish while the ERPs were being recorded. Exploring 
the taxonomic relationships between words will help us to better understand the developing organization of the lexical-semantic system and how young bilingual children form their lexicon. To do so, ERP technique was applied; for it provides temporally accurate information about the neural activity elicited in response to different stages of word processing and requires no overt behaviour from the child, such as motor response or looking.

Here, we explored three ERP components of interest: $\mathrm{N} 2$, N400, and late anterior negativity (LAN). The N2 has been associated with word comprehension or familiarity (Mills et al., 1933, 1997; Conboy \& Mills, 2006; Vihman et al., 2007), whereas the N400 has been related to lexical-semantic integration (e.g., Torkildsen et al., 2007; Kuipers \& Thierry, 2013; Sirri \& Rämä, 2015). While in a few studies the N400 semantic priming effect has been shown to occur over the posterior recording sites (e.g., Friedrich \& Friederici, 2004, 2008; Rämä et al., 2013; Sirri \& Rämä, 2015), an additional anterior negativity has been elicited in response to semantic anomalies (Silva Pereyra, Klarman, Lin \& Kuhl, 2005) and to semantic incongruence between image-word pairs (Friedrich \& Friederici, 2004; Torkildsen et al., 2007). This anterior negativity has been suggested to reflect enhanced image-specific processing of an expected word (Friedrich \& Friederici, 2004) and allocation of attention to the stimuli (e.g., Conboy \& Mills, 2006; Torkildsen, Sannerud, Syversen, Thormodsen, Simonsen, Moen, Smith \& Lindgren, 2006; Torkildsen, Syversen, Simonsen, Moen \& Lindgren, 2007). Measuring these three ERP components will allow us to determine how dual language experience influences different stages of lexical-semantic processing in bilinguals' two languages.

It has been earlier suggested that the efficiency of word recognition (e.g., Marchman et al., 2010; for a review, see DeAnda et al., 2016a) and the speed of semantic integration in one language (Singh, 2014) are related to the increased experience with that language. Based on these findings, we hypothesize that even if bilingual children exhibit sensitivity to taxonomic relationships between words in each of their languages, the occurrence and distribution of ERPs will vary across languages. Consequently, we expect that at the early stages of word processing, the $\mathrm{N} 2$ component will be elicited similarly for both the DL and NDL. However, as it has been argued that the lexical-semantic representations of words in the DL might be stronger and better established than those in the NDL (Singh, 2014), we expect that the occurrence and/or distribution of the N400 component will be modulated across the languages. Also, due to weaker links between words and their meanings in the NDL (Singh, 2014), we expect the lexical-semantic integration to be effortful and to require increased resources allocation. This will be reflected by the occurrence of the LAN in the NDL only, a component that has been previously associated with increase allocation of attention to the stimuli (e.g., Torkildsen et al., 2006, 2007).

\section{Methods}

\section{Participants}

Twenty-three 2 to 4 year-old French-Spanish (11 girls; mean age: 34 months and 22 days; range: 23 months and 19 days to 53 months and 13 days) bilingual children participated in the study. The children were recruited from a database of parents from the local area who voluntarily participated in previous studies in child development in our laboratory. All children were born full-term and presented no hearing deficits or language impairment. Parents were informed about the aim of the study and its procedure before participating and gave informed consent. Children were raised in a family where the mother spoke Spanish and the father French $(n=17)$, the father spoke Spanish and the mother French $(n=2)$, or both parents were bilinguals $(n=2)$. In one family, the mother spoke Spanish and the father Italian and the child was learning French at the day care. In another family, both parents spoke French but the day care giver spoke only Spanish to the child. Parents filled the Language Exposure Questionnaire (Bosh \& SebastiánGálles, 1997) and estimated the amount of their child's total exposure to each language. Similarly to previous research with bilingual children (e.g., Poulin-Dubois, Blaye, Coutya \& Bialystok, 2011; Singh, 2014), only those participants who received at least $25 \%$ exposure to each language were included in the final sample. Of the twenty-three participants, fifteen were mostly exposed to French (60 to $75 \%$ of exposure time, mean exposure time $67 \%$ ) and eight were equally (50\%) exposed to both languages. As participants were mostly or equally exposed to French (e.g., living in Paris, going to French daily care/kindergarten and school), we defined French to be their DL and Spanish their NDL.

Seven additional children were recruited but their data were excluded from the analyses because of insufficient number of trials in one of the experimental conditions $(n=6)$, or had less than $20 \%$ input in one of the languages $(n=1)$. Parents were given the list of words used in the experiment and were asked to evaluate how many words their children understood or understood and produced. The questionnaire was completed for twenty-one of the twenty-three children in our final sample, including one participant for whom only the Spanish part was filled. Parents' estimation revealed that of the lists of words used in the experiment, children understood 91\% (131 words $(S D=21)$; range $82-144)$ and produced $67 \%$ (97 words $(S D=54)$; range: 5-144) of the French words, and understood $75 \%$ (108 words $(S D=36)$; range: $15-144)$ and produced $44 \%$ (63 words $(S D=56)$; range: 
1-139) of the Spanish words. For children who had the questionnaire completed for both languages $(n=20)$, a paired-sample $t$-test comparing the number of words understood $(t(19)=3.62 ; p=0.002)$ and/or produced $(t(19)=3.78 ; p=0.001)$ in French to those in Spanish revealed significant differences. The study was conducted in conformity with the declaration of Helsinki and approved by the Ethics Committee of the University of Paris Descartes.

\section{Stimuli}

The stimuli consisted of French basic level nouns (144 words) and their Spanish translation equivalents (144 words) from different semantic categories (animals, clothes, body parts, food, furniture, transportation, household items, persons, nature and places to go). The words were selected from the French translation and adaptation of the MacArthur Communicative Development Inventory of Words and Sentences (CDI; Fenson, Dale, Reznick, Thal, Bates, Hartung, Pethick \& Reilly, 1993) and from children's books, and then translated into their Spanish equivalents through Internet dictionary. To further ensure that all words in French were translation equivalents (TEs) of the Spanish words and vice-versa, two native speakers of Spanish from our laboratory reviewed the lists. $88 \%$ of the words in French appeared in the French translation and adaptation of the CDI and $84 \%$ of the words in Spanish appeared in the Spanish CDI. The words were presented in four different female voices, two in each language, preventing children from associating one voice to a given language. The speakers were two native speakers of French and two native speakers of Spanish, who were asked to pronounce the words not in an infant directed manner, but in as neutral a way as possible. The 288 words were arranged into two lists of 72 related and 72 unrelated prime-target word pairs in each language. The two lists were then divided into four experimental blocks, two in French and two in Spanish containing each 36 related and 36 unrelated word pairs. The order of the experimental blocks was counterbalanced across participants (i.e., French-Spanish-French-Spanish $(n=11)$ and Spanish-French-Spanish-French $(n=12)$. Words were either taxonomically related (e.g., chien (dog) - âne (donkey) versus perro - burro) or unrelated (e.g., ventre (tummy) - âne (donkey) versus barriga burro) and were neither associatively nor phonologically related. The pairing of each prime and target words consisted of pseudo-randomised combination (while the prime was spoken by one voice, the target by another) and the presentation order of trials within each block was randomized. The mean durations of words were $542 \mathrm{~ms}$ in French and 520ms in Spanish. The recordings were edited with Adobe Audition (CS 5.5) and normalized at $22 \mathrm{kHz}$ sampling rate with Praat (5.3.19).

\section{Procedure}

Children sat by themselves on a chair next to their parents in a dimly lit room at $140 \mathrm{~cm}$ from the two loudspeakers. They were allowed to play with toys or draw with crayons placed on a table in front of them. Parents were instructed not to communicate orally with their children. During the experiment, no visual stimuli were presented. The invariant stimulus onset asynchrony (SOA) was 1000ms and the intertrial interval (ITI) was $2200 \mathrm{~ms}$. In both languages (French and Spanish) each prime and target word was repeated twice, once in the related and once in the unrelated condition. Prime and target words in a given trial were always spoken by two different speakers. The whole experiment lasted approximately 17 minutes.

\section{Event-related potential recordings and data analyses}

The electroencephalogram (EEG) was continuously recorded from a 128-channel Hydrocel Geodesic Sensor Net, referenced online to the vertex $(\mathrm{Cz})$. The raw signal was amplified with an EGI NetAmps 400 amplifier, filtered ( 0.1 to $100 \mathrm{~Hz}$ bandpass) and digitized at $250 \mathrm{~Hz}$ sampling rate. Impedances were kept below a threshold of $100 \mathrm{k} \Omega$. The EEG was filtered offline $(0.3-30 \mathrm{~Hz})$ and segmented into $800 \mathrm{~ms}$ epochs from word onset that were averaged according to a $300-\mathrm{ms}$ pre-stimulus baseline. Eye blinks and eye movements were detected and removed using the ocular artifact removal (OAR) algorithm (Gratton, Coles \& Donchin, 1983). Trials including artifacts exceeding $\pm 170 \mu \mathrm{V}$ were rejected. Data from rejected bad channels were replaced using spherical spline interpolation. Segments including more than 40 bad channels were rejected. We averaged segments separately for each subject, target word type (related and unrelated) and language (French and Spanish) and re-referenced those segments to an average reference. Participants had at least 10 trials per target word type in each language. The mean number of trials was 22 (range: 10 to 54 trials; $S D=12$ ) for related and 24 (range: 10 to 61 trials; $S D=13$ ) for unrelated targets in French and 21 (range: 10 to 58 trials; $S D=11$ ) for related and 20 (range: 11 to 54 trials; $S D=10$ ) for unrelated targets in Spanish.

\section{Data analyses}

The analysis of variance (ANOVA) included as withinsubject factors the trial type (related versus unrelated target word), language (French versus Spanish), area (frontal and posterior), and hemisphere (left versus right) factors. The mean amplitudes were calculated separately for each electrode. The mean amplitudes extracted from nine electrodes over the frontal recording site and from sixteen electrodes over the central-posterior recording site were averaged. The midline electrodes were excluded 
A.

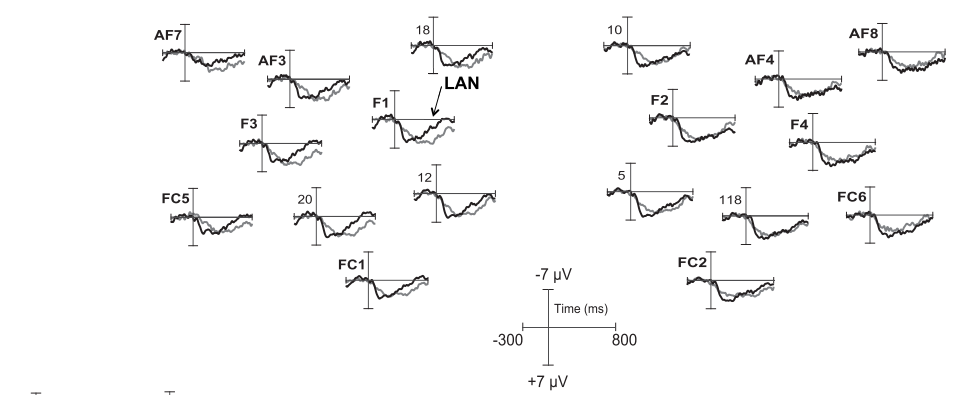

B.
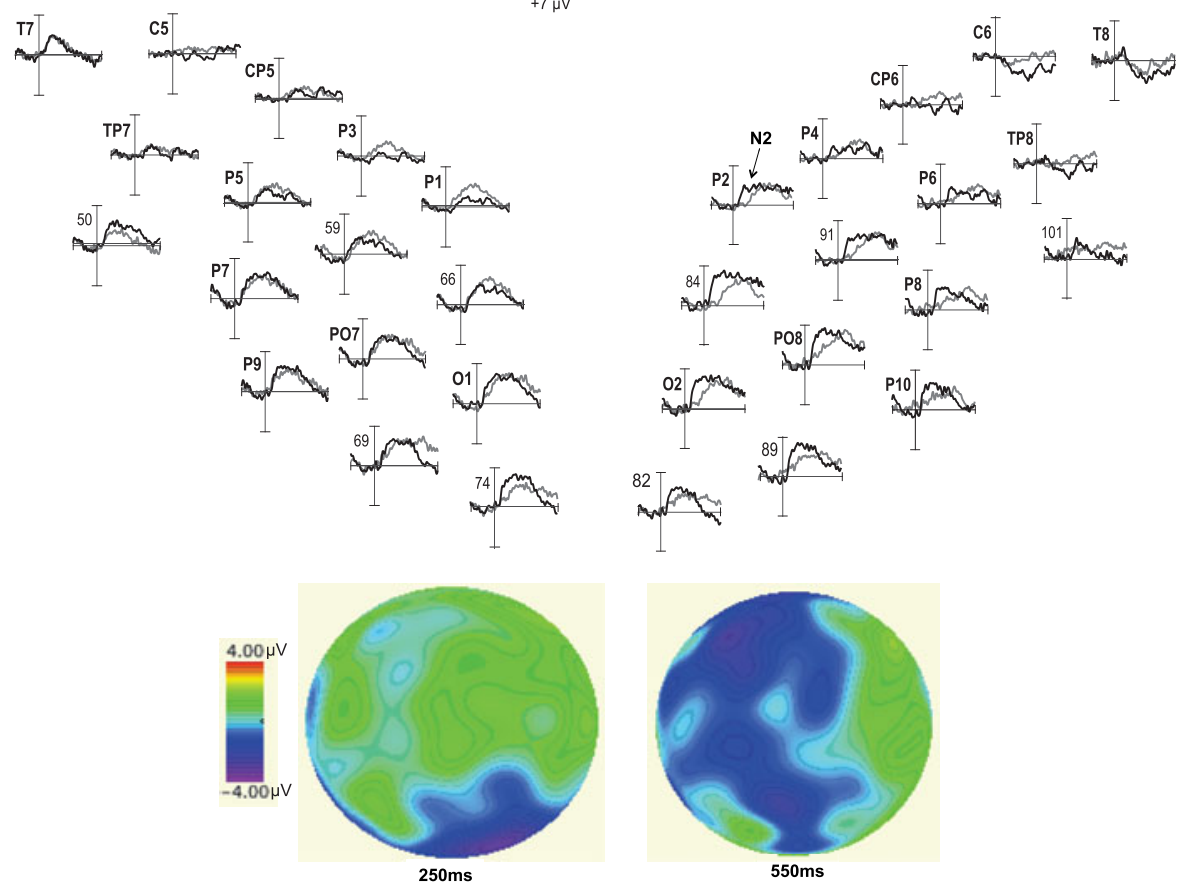

Figure 1A. Grand-averaged waveforms for related (grey line) and unrelated (black line) target words in Spanish over the frontal and posterior recording sites. The vertical lines illustrate the target word onset. The arrows indicate examples of N2 at P2 and LAN at F1 electrode positions. 1B. Difference wave (unrelated - related) topographical maps for Spanish target words, displaying at $250 \mathrm{~ms}$ to illustrate the $\mathrm{N} 2$ and at $550 \mathrm{~ms}$ to illustrate the LAN.

from the statistical analyses, resulting in 50 channels in 4 regions of interest. The 50 channels with their equivalents according to the 10-10 international system of electrodes sites are as follow: 18, 19 (F1), 12, 23 (AF3), 24 (F3), 20, 13 (FC1), 26 (AF7), and 28 (FC5), in the left frontal, 10, 4 (F2), 5, 3 (AF4), 124 (F4), 118, 112 (FC2), 2 (AF8), and 117 (FC6), in the right frontal, 60 (P1), 66, 70 (O1), 74, 52 (P3), 59, 65 (PO7), 69, 47 (CP5), 51 (P5), 58 (P7), 64 (P9), 41 (C5), 46 (TP7), 50, and 45 (T7), in the left central-posterior, and 85 (P2), 84, 83 (O2), 82, 92 (P4), 91, 90 (PO8), 89, 98 (CP6), 97 (P6), 96 (P8), 95 (P10), 103 (C6), 102 (TP8), 101, and 108 (T8), in the right central-posterior recording sites. For the statistical analyses, specific time-windows of interest were chosen, from 400 to $700 \mathrm{~ms}$ (LAN) over the frontal area and from 150 to $350 \mathrm{~ms}(\mathrm{~N} 2)$ and 450 to $750 \mathrm{~ms}(\mathrm{~N} 400)$ over the central-posterior area. The statistical analyses were conducted with SPSS (IBM SPP statistics, version
20) and the Greenhouse-Geisser correction was applied for nonsphericity when appropriate.

\section{Results}

Visual inspection of ERPs in response to target words showed more negative amplitudes of the LAN for unrelated compared to related target words in Spanish (Fig. 1A \& 1B) but not in French (Fig. 2A \& 2B) over the frontal recording sites. The LAN for Spanish target words was more prominent over the left than over the right hemisphere (Fig. 3). Over the central-posterior recording sites, the amplitudes of the N2 and the N400 were more negative for unrelated compared to related target words. However, the occurrence of N400 but not that of N2 component differed across both languages. The N400 was elicited only for French unrelated target words over the right posterior recording sites (Fig. 2A \& 2B). 
A.

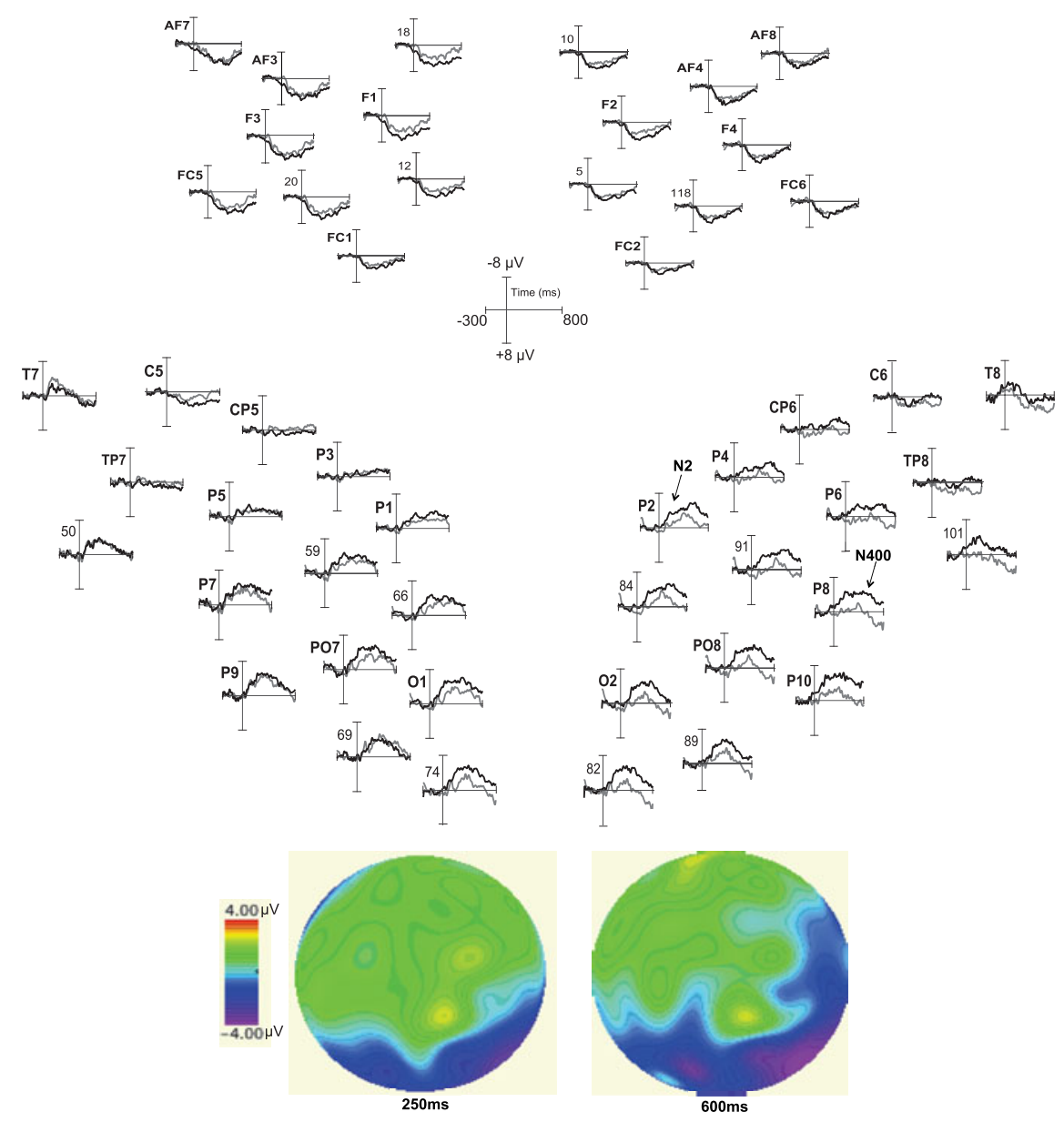

Figure 2A. Grand-averaged waveforms for related (grey line) and unrelated (black line) target words in French over the frontal and posterior recording sites. The vertical lines illustrate the target word onset. The arrows indicate examples of N2 at P2 and N400 at P8 electrode positions. 2B. Difference wave (unrelated - related) topographical maps for French target words, displaying at $250 \mathrm{~ms}$ to illustrate the $\mathrm{N} 2$ and at $600 \mathrm{~ms}$ to illustrate the $\mathrm{N} 400$.

A within-subjects repeated measures of ANOVA was conducted at each recording site to investigate whether the amplitudes and distribution of the LAN, N2, and N400 were modulated according to the language. Here, we report significant main effects and/or interactions only.

Over the frontal recording sites, a three-way ANOVA including 2 (trial type) x 2 (language) $\times 2$ (hemisphere) revealed a significant interaction between trial type $x$ language $x$ hemisphere $(F(1,22)=4.35 ; p=0.05)$, indicating that the amplitudes of the LAN were modulated according to the language and the hemisphere (Fig. 1A \& 1B). Paired-samples $t$-test revealed that the LAN effect (amplitudes for unrelated target words - amplitudes for related target words; Fig. 3) was more prominent for Spanish target words over the left $(-2.10 \mu \mathrm{V})$ than over the right $(0.12 \mu \mathrm{V})$ hemisphere $(t(22)=1.91 ; p=0.07)$; $\left.d^{\prime}=0.43\right)$ whereas for French target words the effect over the left $(1.28 \mu \mathrm{V})$ and the right $(0.57 \mu \mathrm{V})$ did not significantly vary $\left(t(22)=0.91 ; p=0.37 ; d^{\prime}=0.14\right)$.
Over the central-posterior recording sites, a threeway ANOVA including 2 (trial type) $\mathrm{x} 2$ (language) $\mathrm{x}$ 2 (hemisphere) yielded a significant trial type effect on the amplitudes of the $\mathrm{N} 2(F 1,22)=6.91 ; p=0.01)$, showing more negative amplitudes for unrelated $(-2.28 \mu \mathrm{V})$ compared to related $(-1.27 \mu \mathrm{V})$ target words $\left(t(22)=2.63 ; p=.01 ; d^{\prime}=0.56\right)$. However, the interaction between trial type $x$ language $x$ hemisphere $(F(1,22)=0.44 ; p=0.51)$ was not significant, indicating that the amplitudes of the N2 and its distribution were not modulated by the processed language.

In relation to the N400, three-way mixed-measures ANOVA including 2 (trial type) $\times 2$ (language) $\times 2$ (hemisphere) yielded marginal interaction between trial type $x$ language $x$ hemisphere $(F(1,22)=3.73 ; p=0.07)$. For French target words, the main trial type effect was approaching significance over the right $(F(1,22)=3.60$; $p=0.07)$ but not over the left $(F(1,22)=0.10 ; p=0.75)$ hemisphere, while for Spanish target words no such effect 


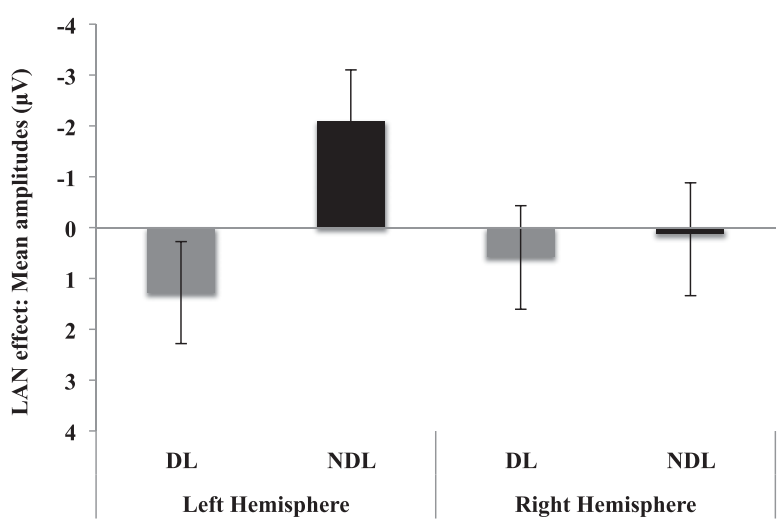

Figure 3. The magnitude of LAN effect for the dominant (French; DL) and the non-dominant (Spanish; NDL) over the left and right hemisphere. Grey columns illustrate the DL while black columns the NDL. The vertical bars illustrate the standard error of means.

was found over the right $(F(1,22)=0.70 ; p=0.41)$ or the left $(F(1,22)=0.17 ; p=0.69)$ hemisphere. For French target words, the effect (amplitudes for unrelated target words - amplitudes for related target words) was more prominent over the right $(-2.83 \mu \mathrm{V})$ than over the left $(-0.37 \mu \mathrm{V})$ hemisphere $\left(t(22)=1.46 ; p=.16 ; d^{\prime}=0.39\right)$ whereas for Spanish target words the effect did not vary across hemispheres $\left(t(22)=0.30 ; p=.77 ; d^{\prime}=0.10\right)$. Over the right hemisphere, the difference between both languages was significant $(t(22)=2.312 ; p=0.03$, $\left.d^{\prime}=0.60\right)$.

\section{Discussion}

The present study aimed to investigate whether children acquiring two languages simultaneously exhibit sensitivity to semantic relatedness between words in each of their languages. To do so, we presented bilingual children with auditory semantic priming task within each of their languages and explored the occurrence and distribution of language-related ERPs. Our results revealed that the posteriorly distributed N2 component was similar in both languages, whereas the occurrence and distribution of the N400 and the LAN varied across the DL (French) and the NDL (Spanish). While the N400 appeared over the right recording sites for target words in the DL only, the LAN appeared over the left frontal recording sites for target words in the NDL only. These results suggest that words are organized according to their taxonomic relationships in each of the bilinguals' languages. However, the variation of ERPs occurrence and distribution across the DL and the NDL suggests that similar and distinct neural mechanisms underpin lexicalsemantic processing in the developing bilingual brain. The former underpin word familiarity whereas the latter drives semantic integration.

The N2 component has been previously associated with processing of word familiarity in monolingual (e.g., Mills et al., 1993, 1997) and bilingual (Conboy \& Mills, 2006; Vihman et al., 2007) children, lexical expectation (Friedrich \& Friederici, 2004) or facilitation (Torkildsen et al., 2007), automatic allocation of attention to familiar words (Thierry, Vihman \& Roberts, 2003), and processing of semantic relatedness (Sirri \& Rämä, 2015). In our study, the $\mathrm{N} 2$ occurred in response to semantic relatedness over the posterior recording sites similarly for both languages, which is in line with previous results obtained with monolingual children (Sirri \& Rämä, 2015). It can be thus suggested that the posteriorly distributed N2 is an indicator of semantic processing for both monolinguals and bilinguals.

On the contrary, the N400 priming effect (more negative amplitudes for unrelated compared to related target words) occurred over the right posterior recording sites for target words in the DL only. The occurrence and distribution of the $\mathrm{N} 400$ for words in the DL is similar to that previously found in monolingual toddlers (e.g., Friedrich \& Friederici, 2004; Torkildsen et al., 2007; Rämä et al., 2013), indicating that lexical-semantic integration might be facilitated only in the language with which participants had been acquiring enhanced experience. Thus, the absence of N400 for the NDL may be explained by the fact that language dominance influences the efficiency of lexical-semantic processing. It has been earlier shown that in young bilinguals, the speed and efficiency of lexical processing in word recognition tasks is related to the vocabulary knowledge within each language (Marchman et al., 2010). In the current study, we did not investigate the total vocabulary size within each language by using normalized measures, such as the MacArthur-Bates communicative development inventory (MCDI). Nevertheless, participants comprehended more of the words used in the experiment that were in the DL (French) than in the NDL (Spanish) and they were currently living in a French environment. This might support the hypothesis that increased linguistic experience in one language strengthens the links between words and their meanings and enhances the efficiency of semantic integration in that particular language (Singh, 2014).

Accordingly, our findings evoke the 'weaker links' hypothesis (e.g., Gollan, Montoya, Fennema-Notestine \& Morris, 2005; Gollan, Montoya, Cera \& Sandoval, 2008) according to which frequency-in-use is a determinant factor for the strength of connection between words in each of the bilinguals' lexical-semantic system. Lesser exposure to one language will result in decreased frequency of use of that language. Consequently, the connections across words in the lexical-semantic system 
of that same language are weakened. On the contrary, the more frequently one language is used, the stronger the connections are, which in turn facilitate the activation of words in the lexical-semantic system. Therefore, the time course of word activation in the bilingual lexicon might differ from that of monolinguals. Moreover, the SOA length has been recently shown to influence the magnitude of the semantic priming in monolingual children (Sirri \& Rämä, 2015). Accordingly, the $1000 \mathrm{~ms}$ SOA used here might not have been sufficient enough to elicit the N400 in response to semantic relatedness in the NDL, which resulted in less efficient semantic processing in that language. Since the links between lexical items in the NDL are weaker than those in the DL, additional time between word pairs might have allowed prime words to activate more efficiently target words in that language.

Alternatively, because the LAN overlapped with the N400 in timing, it might be suggested that bilingual toddlers process semantic relatedness similarly in both their languages but distinct neural mechanisms underpin lexical-semantic processing in each language. In bilingual adults, it has been shown that the patterns of brain activity are modulated by the frequency of use of each language (e.g., Ardal, Donald, Meuter, Muldrew \& Luce, 1990; Weber-Fox \& Neville, 1996), suggesting it is possible that second language learners activate different processes when integrating semantic information (Hahne \& Friederici, 2001). In monolingual (e.g., Friedrich \& Friederici, 2004; Silva Pereyra et al., 2005; Torkildsen et al., 2006, 2007) and bilingual (Conboy \& Mills, 2006) children, the LAN has been suggested to reflect attentional processes. Hence, we can assume that the occurrence of the left LAN indicates that bilingual children were recruiting additional resources for the lexical-semantic integration and allocating increased attention to the stimuli. This indicates that lexical-semantic processing in the NDL is, to some extent, functionally different from that in the DL and that non-identical neural mechanisms might underpin word processing in each language. That is, bilingual children might use different strategies and recruit distinct neural networks when processing semantic relatedness in each of their languages. Although further studies are needed to confirm either of the hypotheses evoked above, the present findings are the first to shed light on the processing of semantic relatedness in children raised bilingually.

According to our findings, we propose that even though bilingual children exhibit sensitivity to taxonomic relationships between words in each of their languages, the mechanisms of lexical-semantic processing vary according to the language with which many children were mostly experienced. This may have influenced the patterns of brain activity, resulting in both similar and distinct neural resources underpinning lexical-semantic processing in each language. Taken together, these findings suggest that even when both languages are acquired early in life, language dominance shapes the patterns of brain activity and determines the efficiency of semantic integration.

In summary, the present findings demonstrate that although early dual acquisition yields sensitivity to semantic relatedness in both languages, other factors such as language dominance, and increased linguistic experience with one language, contribute to the efficiency of lexical-semantic processing in that language. To date, lexical-semantic organization remains understudied compared to other speech-related domains among bilingual toddlers; and the models interpreting bilingual language processing available are mostly based upon results obtained with adults. Thus, we cannot further conclude in which theoretical model our findings fit best as this is the first study to explore the organization of the lexical-semantic systems in the developing bilingual brain. Additionally, our results present few limitations. First, the MacArthur communicative development inventory was measured for French (DL) and Spanish (NDL) and we were not able to explore whether the total vocabulary size in each language influences the amplitudes of the languagerelated ERPs. Also, the age range of participants varied between 2- to 4-years yielding unbalanced subgroups, which could have negatively influenced the statistical analyses. Nonetheless, our results provide new insight into the developing lexical-semantic organization of bilingual children. Further studies are needed to better understand how early dual acquisition might shape the conceptual system(s) and the patterns of brain activity.

\section{Conclusion}

Altogether, the present results showed that bilingual toddlers are sensitive to the taxonomic relationships between words in both acquired languages. Languagerelated ERPs were more pronounced for unrelated compared to related target words, but their occurrence and distribution were modulated according to stage of lexicalsemantic processing and to the language. Our findings suggest that in young bilinguals, both similar and distinct neural resources mediate lexical-semantic processing in each language.

\section{References}

Ardal, S., Donald, M.W., Meuter, R., Muldrew, S., \& Luce, M. (1990). Brain responses to semantic incongruity in bilinguals. Brain and Language, 39(2), 187-205.

Arias-Trejo, N., \& Plunkett, K. (2009). Lexical-semantic priming effects during infancy. Philosophical Transactions 
of the Royal Society of London. Series B. Biological Sciences, 364 (1536), 3633-47.

Arias-Trejo, N., \& Plunkett, K. (2013). What's in a link: associative and taxonomic priming effects in the infant lexicon. Cognition, 128 (2), 214-27.

Bloom, L. (1973). One word at a time: the use of the single-word utterances before syntax. The Hague: Mouton.

Bosch, L., \& Sebastián-Gallés, N. (1997). Native-language recognition abilities in 4-month-old infants from monolingual and bilingual environments. Cognition, 65(1), 33-69.

Bosch, L., \& Sebastián-Gallés, N. (2001). Evidence of early language discrimination abilities in infants from bilingual environments. Infancy, 2(1), 29-49.

Conboy, B.T., \& Mills, D.L. (2006). Two languages, one developing brain: event-related potentials to words in bilingual toddlers. Developmental Science, 9, 1-12.

DeAnda, S., Hendrickson, K., Zesiger, P., Poulin-Dubois, D., \& Friend, M. (2016b). Lexical access in the second year: a cross-linguistic study of monolingual and bilingual vocabulary development. San Diego Linguistic Papers, 6, 14-28.

DeAnda, S., Poulin-Dubois, D., Zesiger, P., \& Friend, M. (2016a). Lexical processing and organization in bilingual first language acquisition: Guiding future research. Psychological Bulletin, 142(6), 655-667.

Delle Luche, C., Durrant, S., Floccia, C., \& Plunkett, K. (2014). Implicit meaning in 18-month-old toddlers. Developmental Science, 17(6), 948-55.

Elman, J., Bates, E., Johnson, M., Karmiloff-Smith, A., Parisi, D., \& Plunkett, K. (1996). Rethinking innateness: A connectionist perspective on development. Cambridge, MA: MIT Press.

Fenson, L., Dale, P., Reznick, S., Thal, D., Bates, E., Hartung, J., Pethick, S., \& Reilly, J. (1993). MacArthur Communicative Development Inventories: User's guide and technical manual. San Diego, CA: Singular Publishing Group.

Fernald, A., Perfors, A., \& Marchman, V.A. (2006). Picking up speed in understanding: speech processing efficiency and vocabulary growth across the $2^{\text {nd }}$ year. Developmental Psychology, 42 (1), 98-116.

Fernald, A., Pinto, J.P., Swingley, D., Weinberg, A., \& McRoberts, G.W. (1998). Rapid gains in speed of verbal processing by infants in the $2^{\text {nd }}$ year. Psychological Science, 9 (3), 228-231.

Friedrich, M., \& Friederici, A.D. (2004). N400-like semantic incongruity effect in 19-month-olds: Processing known words in picture contexts. Journal of Cognitive Neuroscience, 16(8), 1465-1477.

Friedrich, M., \& Friederici, A.D. (2008). Neurophysiological correlates of online word learning in 14-month-old infants. NeurReport, 19(18), 1757-1761.

Ganger, J., \& Brent, M. R. (2004). Reexamining the vocabulary spurt. Developmental Psychology, 40(4), 621-32.

Genesee, F. (2003). Rethinking bilingual acquisition. In J.M. deWaele (Ed.) Bilingualism: Challenges and directions for future research (pp. 158-182). Clevedon, UK: Multilingual Matters.

Genesee, F. (2006). Bilingual first language acquisition. In E. McCardle \& E. Hoff (Eds.), Childhood bilingualism:
Research on infancy through school age, (pp. 45-67). Clevedon, UK: Multilingual Matters.

Gervain, J., \& Werker, J.F. (2013). Prosody cues word order in 7-month-old bilingual infants. Nature Communications, 4, Article number: 1490.

Gollan, T.H., Montoya, R.I., Cera, C., \& Sandoval, T.C. (2008). More use almost always means a smaller frequency effect: aging, bilingualism, and the weaker links hypothesis. Journal of Memory and Language, 58(3), 787-814.

Gollan, T.H., Montoya, R.I., Fennema-Notestine, C., \& Morris, S.K. (2005). Bilingualism affects picture naming but not picture classification. Memory \& Cognition, 33(7), 1220 1234.

Gratton, G., Coles, M.G.H., \& Donchin, E. (1983). A new method for off-line removal of ocular artifacts. Electroencephalography and Clinical Neurophysiology, 55, 468-484.

Hahne, A., \& Friederici, A.D. (2001). Processing a second language: late learners' comprehension mechanisms as revealed by event-related brain potentials. Bilingualism: Language and Cognition, 4(2), 123-141.

Hills, T.T., Maouene, M., Maouene, J., Sheya, A., \& Smith, L. (2009). Longitudinal analysis of early semantic networks preferential attachment or preferential acquisition. Psych Science, 20(6), 729-739.

Hurtado, N., Grüter, T., Marchman, V.A., \& Fernald, A. (2014). Relative language exposure, processing efficiency and vocabulary in Spanish-English bilingual toddlers. Bilingualism: Language and Cogntiion, 17(10), 189-202.

Kuipers, J. R., \& Thierry, G. (2013). ERP-pupil size correlations reveal how bilingualism enhances cognitive flexibility. Cortex, 49 (10), 2853-2860.

Kutas, M., \& Federmeier, K. D. (2011). Thirty years and counting: finding meaning in the N400 component of the event-related brain potential (ERP). Annual Review of Psychology, 62, 621-47.

Legacy, J., Zesiger, P., Friend, M., \& Poulin-Dubois, D. (2016). Vocabulary size, translation equivalents, and efficiency in word recognition in very young bilinguals. Journal of Child Language, 43(4), 760-783.

Marchman, V. A., Fernald, A., \& Hurtado, N. (2010). How vocabulary size in two languages relates to efficiency in spoken word recognition by young Spanish-English bilinguals. Journal of Child Language, 37, 817-840.

Mills, D.L., Coffey-Corina, S., \& Neville, H.J. (1997). Language comprehension and cerebral specialization from 13 to 20 months. Developmental Neuropsychology, 13(3), 397-445.

Mills, D.L., Coffey-Corina, S.A., \& Neville, H. (1993). Language acquisition and cerebral specialization in 20-month-old infants. Journal of Cognitive Neuroscience, 5(3), 317-334.

Oller, D., Eilers, R. E., Urbano, R., \& Cobo-Lewis, A. B. (1997). Development of precursors to speech in infants exposed to two languages. Journal of child language, 24(02), 407-425.

Pearson, B. Z., Fernandez, S. C., \& Oller, D. K. (1993). Lexical development in bilingual infants and toddlers: Comparison to monolingual norms. Language learning, 43(1), 93-120.

Patterson, J. L., \& Pearson, B. Z. (2004). Bilingual lexical development: Influences, contexts, and processes. In B. A. Goldstein (Ed.), Bilingual language development 
and disorders in Spanish- English speakers (pp. 77-104). Baltimore, MD: Paul H. Brookes.

Polka, L., \& Sundara, M. (2003). Word segmentation in monolingual and bilingual infant learners of English and French. In Proceedings of the 15th International Congress of Phonetic Sciences, pp. 1021-1024.

Rämä, P., Sirri, L., \& Serres, J. (2013). Development of lexical-semantic language system: N400 priming effect for spoken words in 18-and 24-month old children. Brain and language, 125(1), 1-10.

Silva Pereyra, J.F., Klarman, L., Lin, L.J-F., \& Kuhl, P. (2005). Sentence processing in 30-month-old children : an eventrelated potential study. NeuroReport, 16(6), 645-648.

Singh, L. (2014). One World, Two Languages: CrossLanguage Semantic Priming in Bilingual Toddlers. Child development, 85(2), 755-766.

Sirri, L., \& Rämä, P. (2015). Cognitive and neural mechanisms underlying semantic priming during language acquisition. Journal of Neurolinguistics, 35, 1-12.

Styles, S. J., \& Plunkett, K. (2009). How do infants build a semantic system? Language and Cognition, 1 (01), 1-24.
Thierry, G., Vihman, M., \& Roberts, M. (2003). Familiar words capture the attention of 11 -month-olds in less than $250 \mathrm{~ms}$. NeuroReport, 14(18), 2307-2310.

Torkildsen, J. von Koss., Sannerud, T., Syversen, G., Thormodsen, R., Simonsen, H.G., Moen, I., Smith, L., \& Lindgren, M. (2006). Semantic organization of basic-level words in 20-month-olds: An ERP study. Journal of Neurolinguistics, 19, 431-454.

Torkildsen, J. von Koss, Syversen, G., Simonsen, H. G., Moen, I., \& Lindgren, M. (2007). Electrophysiological correlates of auditory semantic priming in 24-month-olds. Journal of Neurolinguistics, 20(4), 332-351.

Vihman, M. M., Thierry, G., Lum, J., Keren-Portnoy, T., \& Martin, P. (2007). Onset of word form recognition in English, Welsh, and English-Welsh bilingual infants. Applied Psycholinguistics, 28(3), 475.

Weber-Fox, C.M., \& Neville, H. J. (1996). Maturational constraints on functional specialization for language processing: ERP and behavioral evidence in bilingual speakers. Journal of Cognitive Neuroscience, 8(3), 231256. 